\title{
Mapping plasma structures in the high-latitude ionosphere using beacon satellite, incoherent scatter radar and ground-based magnetometer observations
}

\author{
Jürgen Watermann $\left({ }^{1}\right)$, Gary S. Bust $\left({ }^{2}\right)$, Jeffrey P. Thayer $\left(^{3}\right)$, Torsten Neubert $\left({ }^{4}\right)$ \\ and Clayton Coker $\left(^{2}\right)$ \\ $\left.{ }^{1}\right)$ Danish Meteorological Institute, Copenhagen, Denmark \\ ${ }^{2}$ ) Applied Research Laboratories, The University of Texas at Austin, TX, U.S.A. \\ $\left(^{3}\right)$ SRI International, Menlo Park, CA, U.S.A. \\ $\left({ }^{4}\right)$ Danish Space Research Institute, Copenhagen, Denmark
}

\begin{abstract}
In the autumn of the year 2000, four radio receivers capable of tracking various beacon satellites were set up along the southwestern coast of Greenland. They are used to reconstruct images of the ionospheric plasma density distribution via the tomographic method. In order to test and validate tomographic imaging under the highly variable conditions often prevailing in the high-latitude ionosphere, a time interval was selected when the Sondrestrom incoherent scatter radar conducted measurements of the ionospheric plasma density while the radio receivers tracked a number of beacon satellites. A comparison between two-dimensional images of the plasma density distribution obtained from the radar and the satellite receivers revealed generally good agreement between radar measurements and tomographic images. Observed discrepancies can be attributed to $F$ region plasma patches moving through the field of view with a speed of several hundred meters per second, thereby smearing out the tomographic image. A notable mismatch occurred around local magnetic midnight when a magnetospheric substorm breakup occurred in the vicinity of southwest Greenland (identified from ground-based magnetometer observations). The breakup was associated with a sudden intensification of the westward auroral electrojet which was centered at about $69^{\circ}$ and extended up to some $73^{\circ}$ corrected geomagnetic latitude. Ground-based magnetometer data may thus have the potential of indicating when the tomographic method is at risk and may fail. We finally outline the application of tomographic imaging, when combined with magnetic field data, to estimate ionospheric Joule heating rates.
\end{abstract}

Key words high-latitude ionosphere - ionospheric tomography - magnetospheric substorm - auroral electrojet-Joule heating

Mailing address: Dr. Jürgen Watermann, Danish Meteorological Institute, Solar-Terrestrial Physics Division, Lyngbyvej 100, DK-2100 Copenhagen Ø, Denmark; e-mail: jfw@dmi.dk

\section{Introduction}

The high-latitude ionosphere is strongly coupled to the magnetosphere and influenced by its dynamic variations. The magnetosphere responds to variations of the solar wind (a stream of ionized particles, predominantly protons and electrons) and the embedded interplanetary magnetic field and thus ultimately to solar activity. The most important solar wind parameters which have significant bearing on the state of the 
magnetosphere are plasma density, temperature, bulk speed, and the magnitude and orientation of the interplanetary magnetic field. Variations in these parameters lead to variations of the state of the magnetosphere through electrodynamic interaction. They are eventually propagated to the high-latitude ionosphere via electric fields, fieldaligned currents and energetic particle precipitation. The coupled solar wind-magnetosphereionosphere system is generally very dynamic during and just after solar maximum (the most recent of which occurred in the years 2000-2001). Since solar wind-magnetosphere-ionosphere interaction is most direct in the auroral zone and polar cap in a broad sense (i.e. at geomagnetic latitudes exceeding some $\pm 60^{\circ}$ ) the high-latitude ionosphere can be highly variable on time scales of solar wind changes, which may be less than a few minutes. Ionospheric effects at high latitudes are particularly dramatic when the interplanetary magnetic field is oriented southward (i.e. opposite to the main geomagnetic field), in which case field line merging can occur, or when its orientation fluctuates a great deal.

In recent years, with the advent of satellites equipped with stable multi-frequency radio transmitters (beacon satellites) the method of ionospheric tomography has become an important tool for imaging the ionospheric plasma density distribution. Various measurement techniques, based on satellite-to-ground or satellite-to-satellite observations of the Total Electron Content (TEC), and different inversion schemes have been developed. Initially, a differential Doppler technique was applied simultaneously to a meridian chain of receivers in order to determine the latitudinal variation of TEC profiles (Leitinger et al., 1984). Subsequently, computer tomography was developed to produce 2D images of the ionospheric plasma density (Austen et al., 1988). The image reconstruction algorithm was further developed in various ways (e.g., Vasicek and Kronschnabl, 1995) to improve its accuracy. The tomographic method has successfully been applied to the mid-latitude ionosphere (e.g., Bust et al., 1997) where the ionosphere tends to be stationary over the time interval needed for tomographic inversion (typically up to $20 \mathrm{~min}$, depending on the satellites tracked). Application of the method to high geomagnetic latitudes (auroral zone and polar cap) has also been reported (e.g., Mitchell et al., 1995; Pryse et al., 1997) though little experience has yet been gained. Bernhardt et al. (1998) present tomographic images of the ionospheric trough and of narrow auroral arcs obtained at high latitudes under stable ionospheric conditions.

Since the ionosphere tends to be very variable at high geomagnetic latitudes, where its state may change on time scales shorter than those needed to collect reasonably complete satellite observations for reconstructing tomographic images, satisfactory performance of the tomographic method is not yet confirmed. In order to address some of the problems of tomographic imaging at high latitudes, a chain consisting of four satellite receivers was set up along the southwestern coast of Greenland, colocated with several ground-based magne-tometer stations and the Sondrestrom Incoherent Scatter Radar (ISR) facility. The ionospheric plasma density distribution, among other parameters, can be derived from ISR measurements on relatively short time scales and be compared with tomographic images obtained from beacon satellite observations. We thus have a procedure at hand to test the tomographic method at high latitudes, validate it if possible, and try to determine under which conditions it fails.

Similar verification concepts were employed by Foster et al. (1994) and Mitchell et al. (1995). The former examined storm-time observations of the mid-latitude ionosphere and showed that largescale discrete $F$ region ionization enhancements and a deep ionospheric trough were recognized in both, incoherent scatter radar data and tomographic images. The latter demonstrated, by comparing tomographic images with EISCAT observations of the ionospheric plasma density, that the tomographic method can render accurate results in the auroral zone if the ionosphere remains stable.

Next we give a description of the experiment, specifically of the instruments used. This is followed by an evaluation of the performance of the tomographic method. We then outline the estimation of Joule heating as a science application well suited for the particular situation in Greenland. We finally summarize the results and elaborate on future work. 


\section{Experiment description}

A map of Greenland is reproduced in fig. 1. It shows the magnetometer sites of the Danish Meteorological Institute (DMI), the satellite receiver stations of the Applied Research Laboratories at the University of Texas, Austin (ARL:UT), and the Sondrestrom Incoherent Scatter

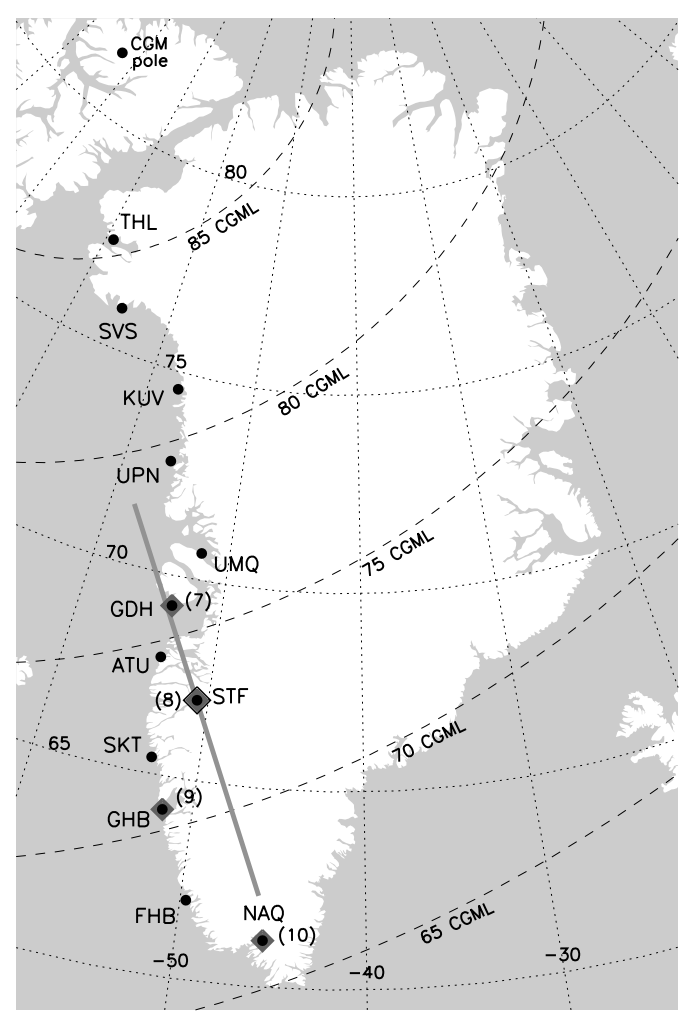

Fig. 1. Greenland with the magnetometer sites of the Danish Meteorological Institute, DMI (full black circles with three-letter station codes), the satellite receiver stations of the Applied Research Laboratories at the University of Texas, Austin, ARL:UT (full gray diamonds with numbers), and the Sondrestrom (STF) Incoherent Scatter Radar facility operated by SRI International (open black diamond). Geomagnetic latitude contours (dashed) are plotted in addition to geographic coordinates (dotted), and the ISR antenna scan trace at $350 \mathrm{~km}$ altitude is marked by a heavy line.
Radar facility operated by SRI International. Those instruments were used for this study and are described below. The southern part of Greenland is most often located in the auroral zone and the central and northern parts in the polar cap. The boundary between auroral zone and polar cap is often found in the vicinity of Sondrestrom but can also shift considerably in latitude, depending on the local time and interplanetary medium. We are thus in a situation where we apply tomographic imaging to the latitudes which cover both, auroral zone and polar cap.

\subsection{Satellite radio receivers}

The Coherent Ionospheric Doppler Receiver (CIDR) was developed at ARL:UT. It is capable of tracking the coherent beacon from the Navy Ionospheric Measurements Satellites (NIMS) as well as other satellites including RADCAL, ARGOS and GFO, and can receive three different satellites simultaneously at data rates up to $1 \mathrm{kHz}$. The measurements from an array of receivers are converted into relative TEC profiles and ingested into an inversion algorithm which renders a threedimensional image of the ionospheric plasma density distribution. For an outline of the algorithm consult a recent paper by Bust et al. (2001) and references therein. For our paper, twodimensional maps in a specific vertical plane were extracted from the 3D inversion results in order to facilitate comparison with radar and magnetometer measurements. The tomography algorithm requires, in its present form, an ionospheric plasma density pattern which is stationary over the time of the radio reception, typically between 10 and $20 \mathrm{~min}$.

\subsection{Incoherent scatter radar}

The Sondrestrom Incoherent Scatter Radar (Kelly, 1983) utilizes techniques which allow the direct measurement of basic ionospheric plasma parameters along the radar beam, including electron number density, electron and ion temperatures, and ion line-of-sight velocity. The 32-m parabolic antenna is fully steerable which 
allows, for instance, to determine the plasma density distribution in a vertical plane oriented along the magnetic meridian through Sondrestrom.

We operated the radar in a mode in which the antenna performs a sequence of elevation scans between geomagnetic north (at a declination of $-27^{\circ}$ from geographic north) and geomagnetic south. Each scan started at an elevation of $30^{\circ}$ toward geomagnetic north, went through the zenith to geomagnetic south, stopped at an elevation of $30^{\circ}$, and returned the same way but in opposite sense, with a one-way scan taking about four minutes to complete. The antenna speed changed with elevation, using a lower velocity at lower elevation and higher velocity overhead, in order to provide equal ground distance increments irrespective of elevation angle. This also compensates for the greater signal power loss for lower elevation angles (longer distance from ionosphere).

We used a signal integration time of $20 \mathrm{~s}$ which overhead is equivalent to about $100 \mathrm{~km}$ integration width at $350 \mathrm{~km}$. The $1.3 \mathrm{GHz}$ two-channel radar transmitter was operated using an alternating code and a 320- $\mu$ s long pulse the latter of which gives a range resolution of about $48 \mathrm{~km}$ with sufficient return signal strength from the $F$ region. The alternating code provides $3-\mathrm{km}$ range resolution but $F$ region backscatter is usually too weak to render reliable results. Tomographic images in the antenna scan plane were then compared with twodimensional electron density maps produced from individual 4-min ISR scans centered on the time interval used for tomographic reconstruction.

\subsection{Magnetometer chain}

The Greenland west coast magnetometer chain (Friis-Christensen et al., 1985) comprises 12 variometer stations along the west coast of Greenland, complemented by three geomagnetic observatories (colocated with variometer stations). The stations are approximately lined up along the same corrected geomagnetic (CGM) meridian so that they order quite naturally according to CGM latitude. The magnetometers sense the magnetic field of electric currents in the ionospheric $E$ region (basically Hall currents, also known as auroral electrojets). The magnetograms can be numerically inverted to infer the temporal and spatial distribution of the equivalent ionospheric current (thinsheet ionospheric Hall current assumed to flow at a mean $E$ region height of between 110 and $115 \mathrm{~km}$ ) crossing the magnetometer chain (Popov et al., 2001). The current density depends linearly on the product of electric field and Hall conductance (height-integrated conductivity) the latter of which depends primarily on the electron density profile, c.f. Section 4. Significant variations in the current strength indicate significant variations of the electric field or the electron density or both. The magnetometer chain can thus serve as an indicator of a changing ionosphere which potentially poses problems to the tomographic method by rendering its assumption of stationary plasma density distribution invalid. On the other hand, can the magnetometers serve to complement tomographic images by providing a means to estimate the ionospheric electric field and Joule heating rate.

\section{Performance evaluation}

In order to test the reliability of the tomographic method at high magnetic latitudes under various ionospheric conditions, we compared tomographic images obtained over southwest Greenland with measurements from the Sondrestrom ISR.

The time interval chosen for comparison covers the night from September 29, 2000, 2145 UT through September 30, 2000, 0500 UT during which the radar operated in the mode described above. This interval compares to 1820-0135 Solar Local Time (SLT) and 1930-0245 Magnetic Local Time (MLT). The ionosphere was practically absent at $\mathrm{E}$ region altitudes, and only $F$ region measurements above some $170 \mathrm{~km}$ are compared. It appears that the $F$ region is sufficiently dynamic to pose problems so that it can well serve to test the tomographic method.

Figure 2 shows the $F$ region plasma density obtained from ISR measurements at a reference altitude of $350 \mathrm{~km}$ in a latitude-time diagram. The plasma density appears to vary significantly over latitude and time. At $0400 \mathrm{UT}$, for instance, we find $1.5 \cdot 10^{11} \mathrm{~m}^{-3}$ around $72^{\circ}$ and more than $10^{12} \mathrm{~m}^{-3}$ poleward of $75^{\circ}$ geomagnetic latitude. More critical 


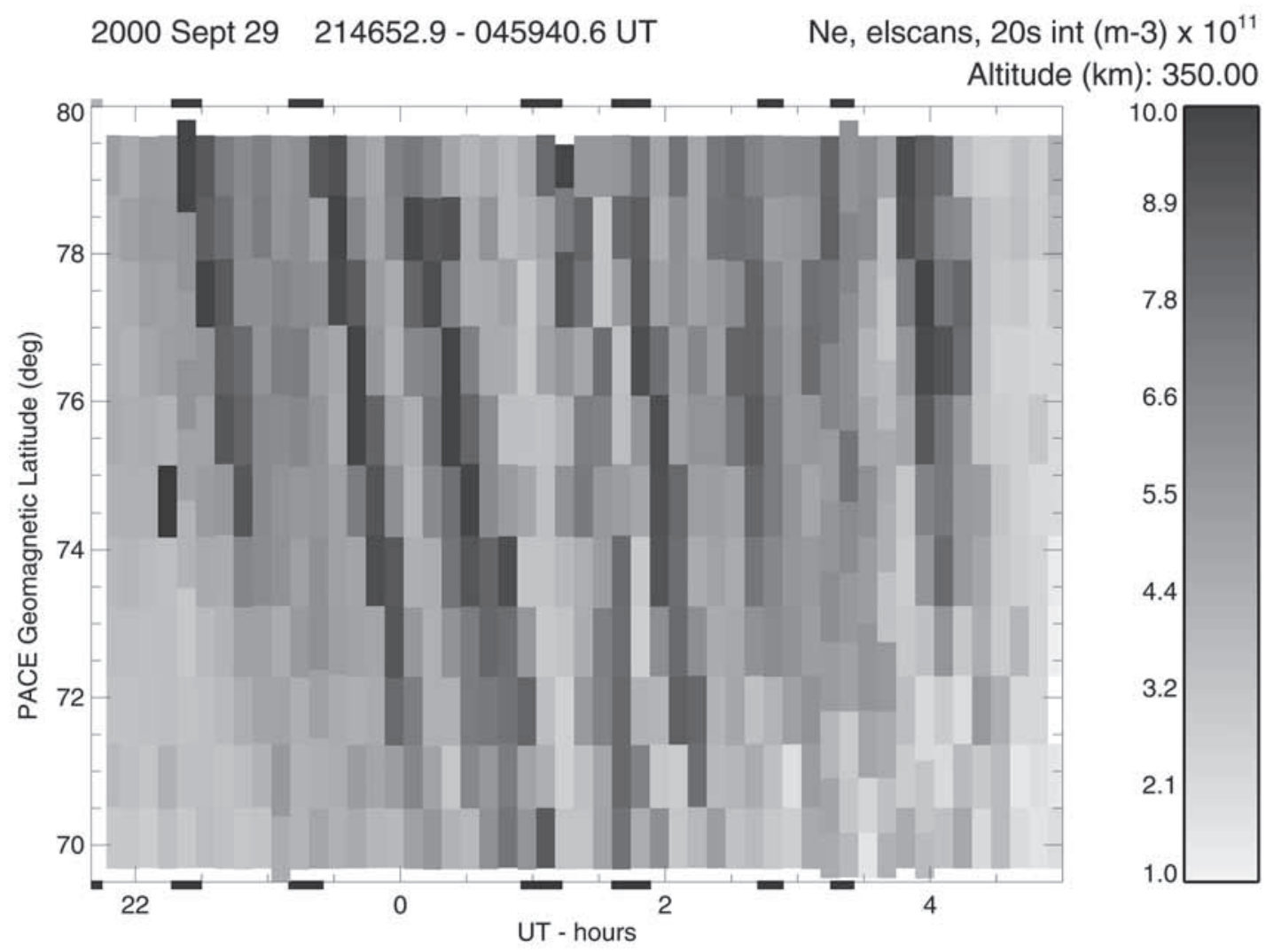

Fig. 2. $F$ region ( $350 \mathrm{~km}$ altitude) plasma density in a latitude-time diagram, obtained from ISR measurements. Each rectangle represents one 20-s integration cell expanded to the 8-min duration of the respective back-and-forth scan. The full rectangles along the top and bottom abscissae represent the time intervals from which satellite radio signals were used to reconstruct tomographic images.

to the tomographic method is the temporal variation which becomes apparent through a sequence of high-density $\left(\geq 10^{12} \mathrm{~m}^{-3}\right)$ plasma patches about two degrees wide in latitude which move through the ISR scan plane with an equatorward velocity component between 200 and $600 \mathrm{~m} / \mathrm{s}$. Seven 3D tomographic images were obtained during this time period, and cross sections along the radar scan plane were extracted. The satellite reception time intervals which were used for image reconstruction are marked by rectangles along the top and bottom abscissae.

Five out of the seven tomographic images show good agreement with ISR electron density maps inferred from scans centered on the reconstruction intervals. The 0247 UT case is shown as an example of good agreement in fig. 3a. The tomographic image taken around 0247 UT (contour lines) is laid over the plasma density map obtained from the 0247-0251 UT ISR scan (color-coded). The display is centered on Sondrestrom, with ground distance projected from range and elevation on a spherical earth, such that «0» refers to the Sondrestrom ISR location. The two density peaks at about $350 \mathrm{~km}$ height, one above the radar and the other some 500$550 \mathrm{~km}$ to the north, are well reproduced in the tomographic image as is the total extent of the plasma structure. The fit would be even better if the tomographic image were shifted down in altitude by $20-30 \mathrm{~km}$. 

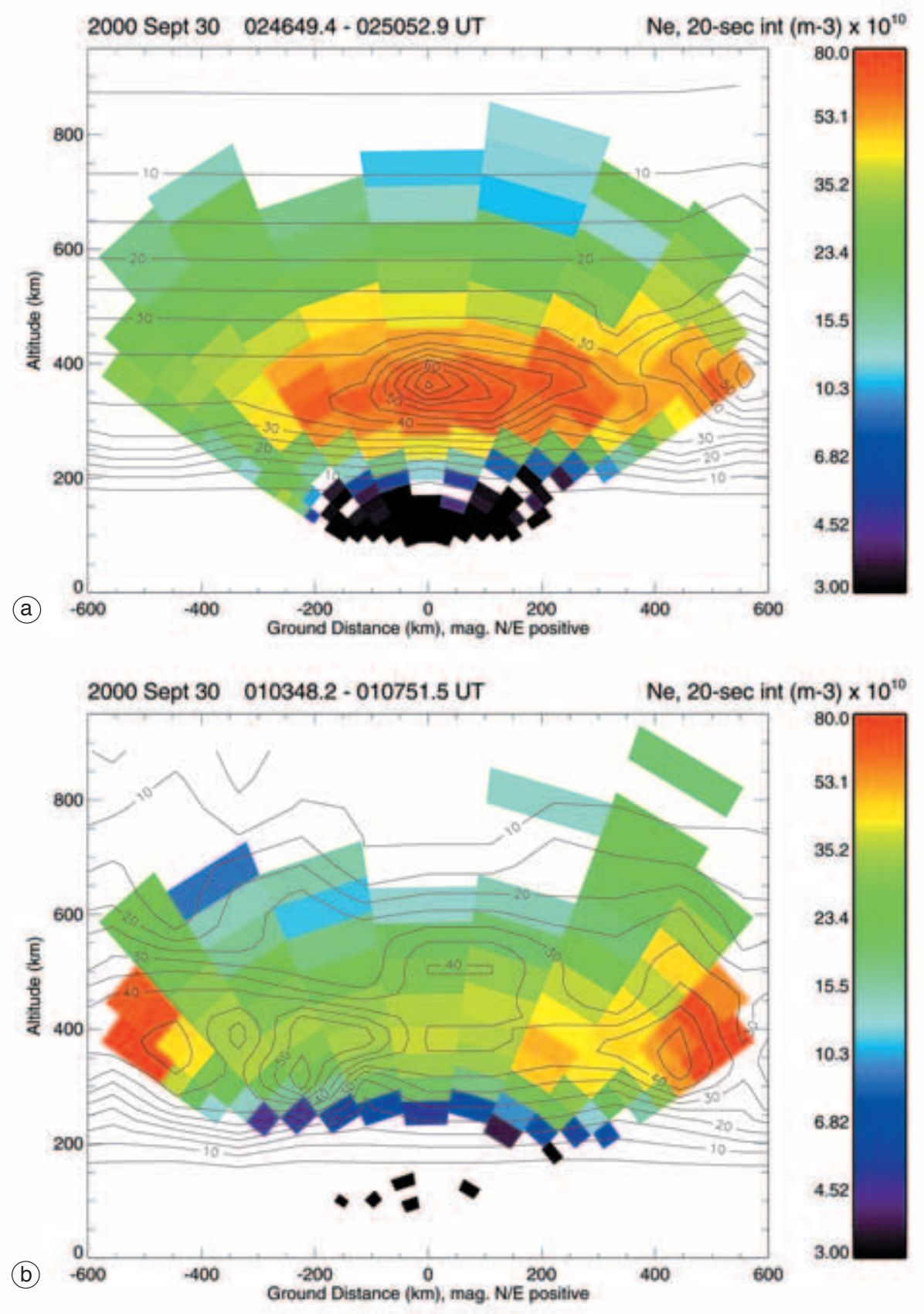

Fig. 3a,b. a) Electron density map from ISR measurements in the vertical plane of the antenna scan which lasted from 024649 UT through 025052 UT, and tomographic image reconstructed in the same reference plane as the antenna scan, centered on 0247 UT. $0 \mathrm{~km}$ ground distance and $0 \mathrm{~km}$ range refer to the Sondrestrom ISR site (STF). b) as (a) but for the 010348-010751 UT radar scan and the 0106 UT tomographic image, respectively. 


\section{GREENLAND WEST COAST MAGNETIC FIELD VARIATIONS}

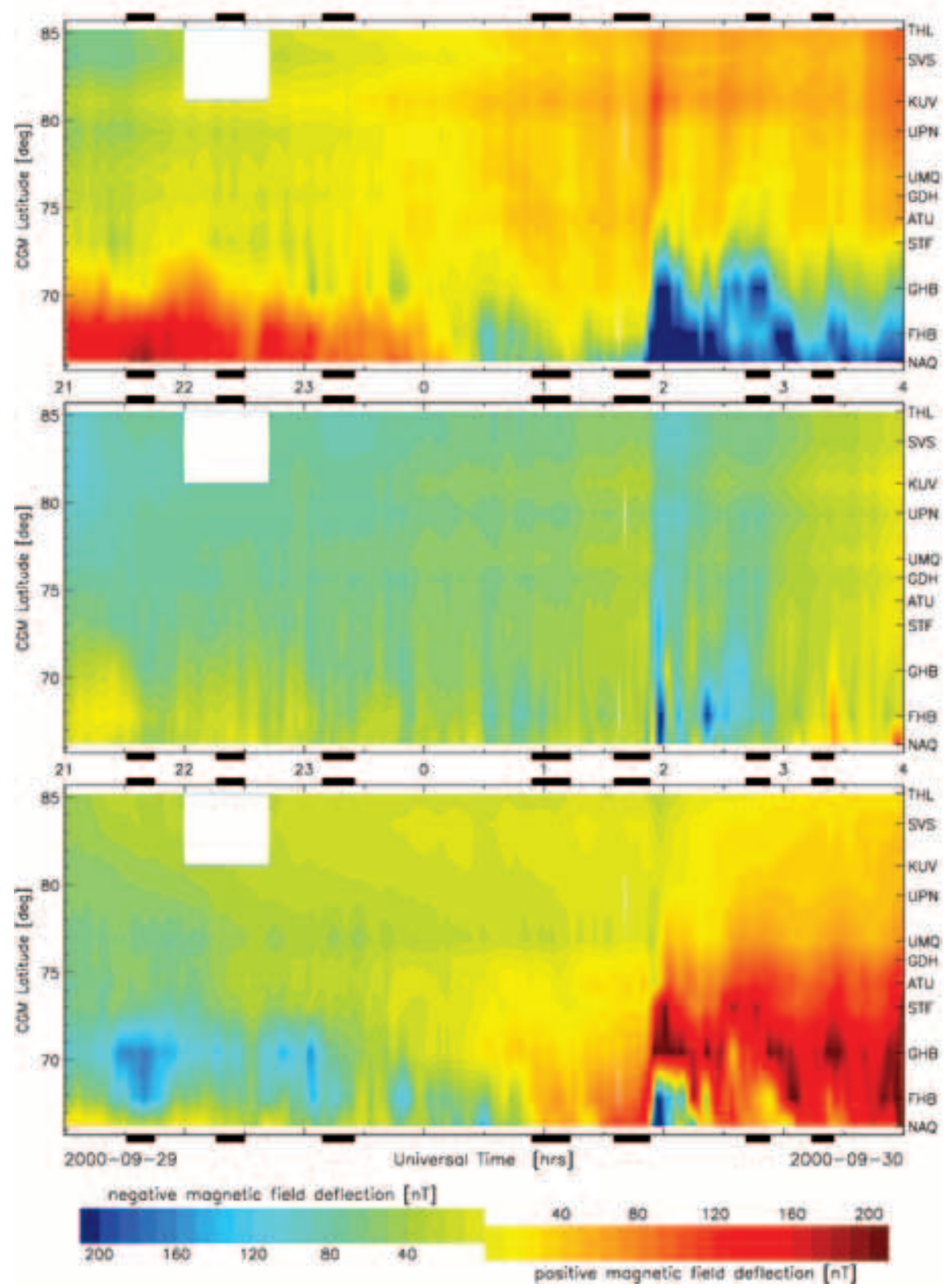

Fig. 4. Low-pass filtered magnetic field variations along the Greenland west coast ( 5 min cutoff), separated into geomagnetic north, east and vertical components. Since all stations approximately line up along the same corrected geomagnetic (CGM) meridian the magnetic field amplitude is plotted in a CGM latitude versus time diagram. The stations are listed along the right-hand ordinate at their respective CGM latitude. The magnetic field intensity is colorcoded and white areas denote missing data. 
The 0106 UT tomographic image shows partial agreement with simultaneous ISR observations (fig. 3b). The enhanced plasma density structures at the poleward and equatorward edges of the ISR antenna scan field, again at about $350 \mathrm{~km}$ height, are well reproduced in the tomographic image. The latter, however, shows an additional $350-\mathrm{km}$ altitude peak 200-250 km south of STF, i.e. around $72^{\circ}$ geomagnetic latitude, which does not appear in the 0104-0108 UT radar scan, and a minor peak at $500 \mathrm{~km}$ altitude on a field line just north of the radar. The major peak does appear, though, in the preceding ISR scan, a few minutes earlier. That scan falls within the satellite reception interval ( $c f$. fig. 2) so that the structure seen in that scan but not later is likely to be representative for the extra peak resolved in the tomographic image.
The 0145 UT image (not shown) agrees poorly with ISR measurements. This, too, can possibly be explained by the particularly disturbed state of the high-latitude ionosphere. The ISR scan sequence coincident with the tomographic reconstruction interval (0135-0153 UT) reveals first the development and decay of mixed plasma density enhancements lacking uniform propagation characteristics, and then, from 0147 UT on, a new well defined equatorward moving plasma patch. The latter interval (after 0147 UT) is largely (though not entirely satisfactorily) reproduced in the tomographic image while the former, more turbulent interval, is not.

The poorly matching 0145 UT case is interesting because of the geophysical conditions prevailing as inferred from ground-based magnetic field observations. Figure 4 reveals that the horizontal magnetic field in the equatorward
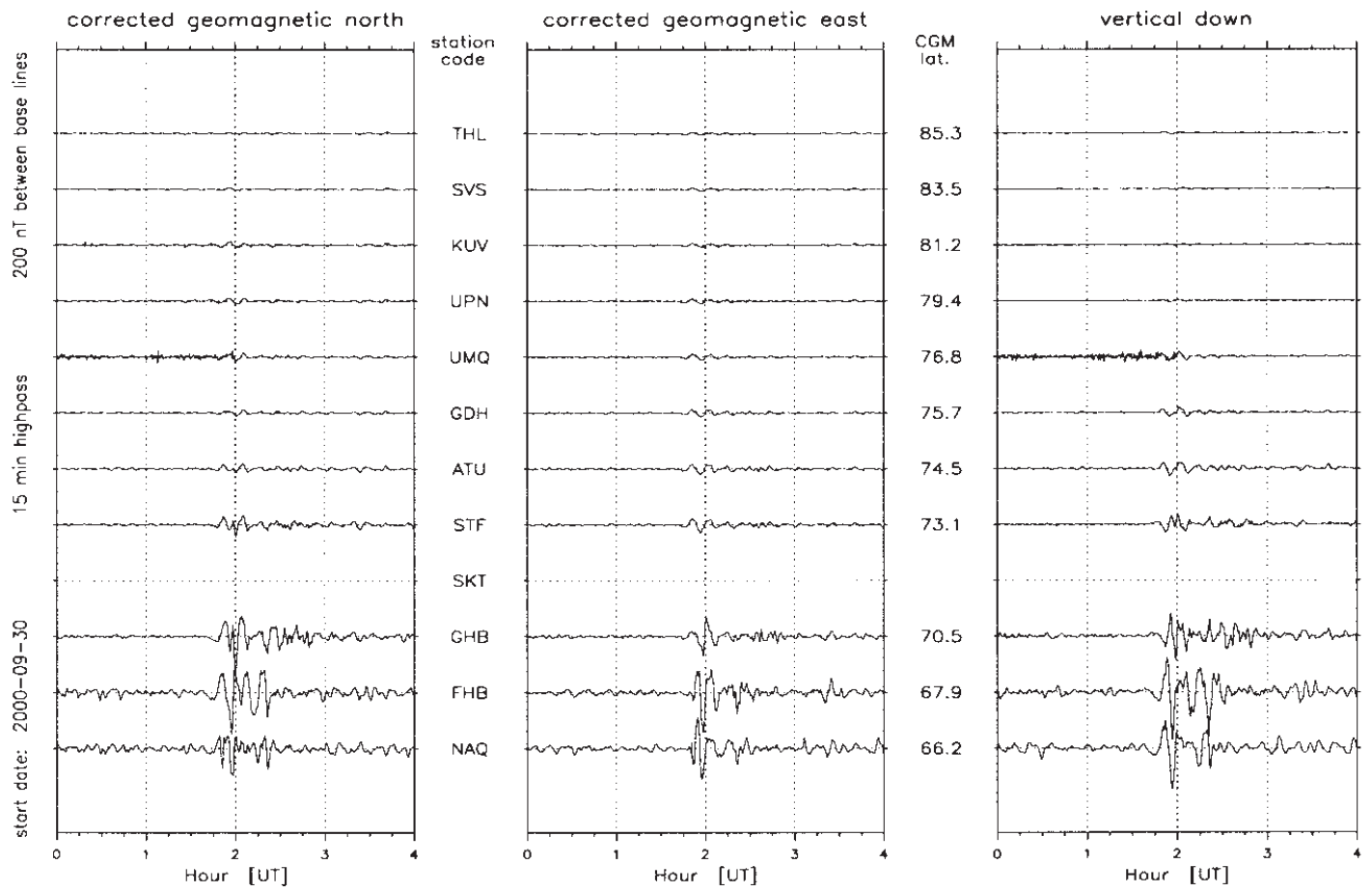

Fig. 5. Stacked high-pass filtered magnetic field variations along the Greenland west coast (15 min cutoff ), separated into geomagnetic north, east and vertical components. 


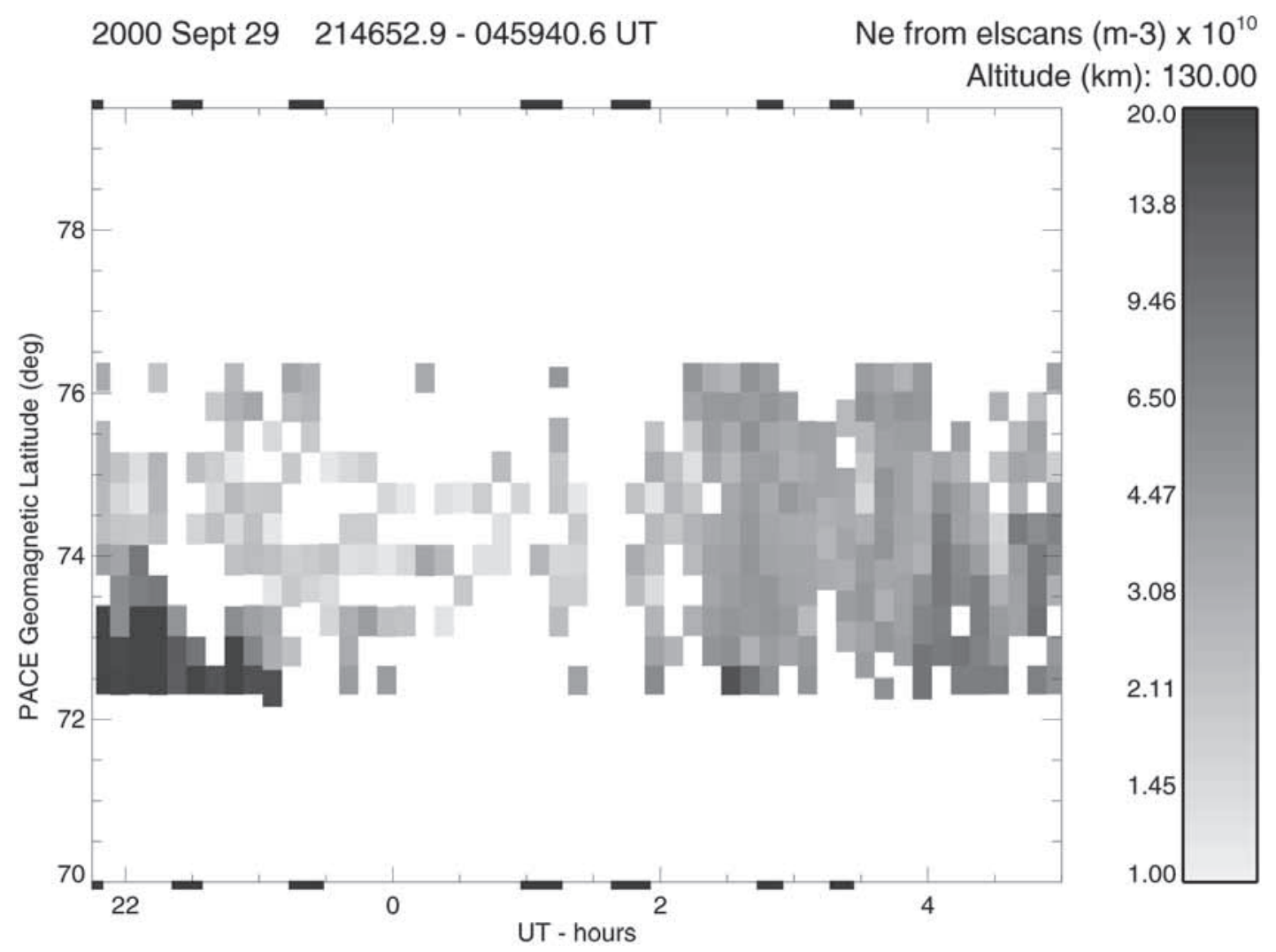

Fig. 6. $E$ region (130 km altitude) plasma density distribution in a format similar to fig. 2 .

section of the magnetometer chain was positive (northward) in the beginning and decreased after $23 \mathrm{UT}$ to values around zero. At about $0145 \mathrm{UT}$ it decreased suddenly to become strongly negative (southward). The vertical component was negative (upward) in the beginning, approached zero after 23 UT and at 0145 UT increased suddenly, simultaneously with the horizontal field, thereby exhibiting a steep latitudinal gradient from negative (upward) below $70^{\circ}$ to positive (downward) above $70^{\circ} \mathrm{CGM}$ latitude. This is equivalent to a westward ionospheric current centered at about $70^{\circ}$ and extending up to some $73^{\circ} \mathrm{CGM}$ latitude. The electrojet intensification is accompanied by the start of magnetic $P i 2$ pulsations at 0145 UT with highest amplitudes between $66^{\circ}$ and $70^{\circ} \mathrm{CGM}$ latitude and lasting for more than half an hour (fig. 5). Taken together these observations are convincing substorm onset indicators. ISR measurements of the plasma density at $E$ region height confirm our view. Figure 6 shows, in a format similar to fig. 2, that the plasma is tenuous at $130 \mathrm{~km}$ altitude prior to 0145 UT but increases to some $3 \cdot 10^{10} \mathrm{~m}^{-3}$ after 0145 UT (in the middle of the night, at 2220 SLT and 2330 MLT). This is most likely a consequence of auroral electron precipitation (electrons with a characteristic energy of several $\mathrm{keV}$ ). It may turn out that the onset of a magnetospheric substorm will frequently pose a problem to the tomographic method, but a firm conclusion can only be drawn once more cases have been investigated.

For the six cases of good and partial agreement between ISR and tomography images we attempted to determine whether the match is improved by shifting the images against each other, in altitude as well as horizontally. This was done in a semi- 
Tomography vs. ISR Plasma Density Image Shift

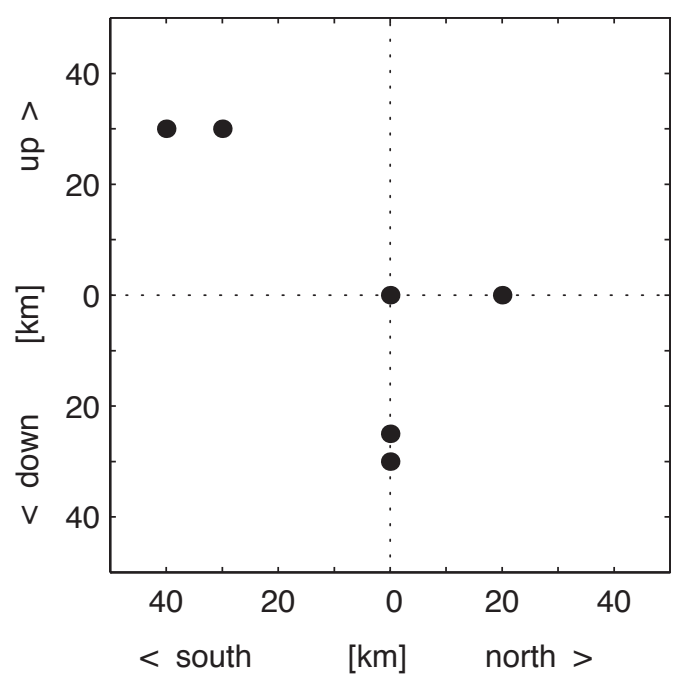

Fig. 7. Horizontal and vertical shifts applied to the six tomographic images which agreed well or partially with Sondrestrom ISR observations, in order to achieve best agreement with the ISR plasma density maps.

quantitative way by fitting the peaks and certain contours visually. It appeared that no substantial improvement can be gained by shifting the images. Figure 7 shows the shifts applied to the tomographic images against the radar maps in order to obtain the best match. They can amount to some $40 \mathrm{~km}$ in horizontal and $30 \mathrm{~km}$ in vertical direction which is not more than the inherent resolution of the radar and radio beacon measurements in this experiment. The figure further reveals that the shift is probably randomly distributed. We are thus confident that tomographic reconstruction was not systematically biased with respect to ISR observations.

\section{Joule heating inference}

Inference of ionospheric Joule heating rates constitutes one of our research objectives and one reason for operating satellite receivers colocated with magnetometers. Joule heating is among the important high-latitude processes of transferring energy from the magnetosphere to the upper atmosphere, which ultimately means energy from the sun via the solar wind into the atmosphere. Joule heating is thus a process which governs an important part of the effect the dynamic sun exercises on the terrestrial environment. While incoherent scatter radar measurements remain a superb way to determine Joule heating rates, they suffer from limited radar operation time, a constrained radar field-of-view, and a multitude of antenna and transmitter modes not all of which are suitable for that purpose. A combination of ground-based magnetometer observations (basically measurements of the ionospheric Hall current) and tomographic plasma density images yields, under certain conditions, estimates of the Joule heating rate on a fairly regular basis. Magnetometer measurements are performed continuously, and radio satellite reception occurs about 20 times per day, though at irregular time intervals.

Since most of the energy transfer from the magnetosphere into the upper atmosphere occurs in the lower ionosphere (below some $200 \mathrm{~km}$ altitude), sufficient resolution of the ionospheric $E$ region is necessary for our method to work. The capability of the tomographic method to resolve an $E$ region plasma density enhancement was demonstrated by Mitchell et al. (1995) who used almost simultaneous EISCAT incoherent scatter radar and beacon satellite observations above Northern Scandinavia. Our tomography versus ISR comparison discussed in the previous section is based on night time observations when $E$ region ionisation was practically absent. However, prior to the start of the ISR operation, tomographic images were reconstructed which indeed show the presence of plasma in the $E$ region, see fig. 8. Note that the plasma density increases to more than $10 \cdot 10^{10} \mathrm{~m}^{-3}$ just below a $5 \cdot 10^{10} \mathrm{~m}^{-3}$ valley observed at $150 \mathrm{~km}$ altitude in the center, and also in a blob located at $-800 \mathrm{~km}$ ground range and $100 \mathrm{~km}$ altitude. We lack, however, quantitative confirmation from radar observations.

If we impose the condition of zero neutral wind speed in the ionosphere as a first approximation, we can derive Joule heating rates 


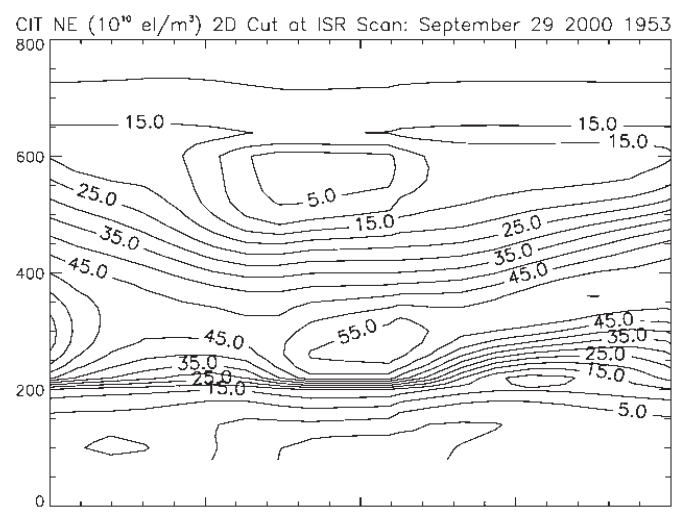

Fig. 8. Tomographic image reconstructed from satellite passes around 2000 UT, prior to the start of the incoherent scatter radar operation.

in the following way. The ionospheric Pedersen and Hall current densities, $j_{P}$ and $j_{H}$, read

$$
j_{P, H}=\sigma_{P, H} E
$$

where $\sigma_{P}$ and $\sigma_{H}$ denote the Pedersen and Hall conductivities, respectively, and $E$ the (horizontal) electric field. Since the ionospheric electric field does not change along the magnetic field line because of the prevailing high parallel conductivity which exceeds the Hall and Pedersen conductivities by orders of magnitude, height-integrated conductivities and current densities can be used and are in the following represented by capital letters. From eq. (4.1) we obtain

$$
J_{H}=\Sigma_{H} E \Rightarrow E=\frac{J_{H}}{\Sigma_{H}}
$$

and further

$$
J_{P}=\Sigma_{P} E=\frac{\Sigma_{P}}{\Sigma_{H}} J_{H}
$$

which leads to an estimate of the height-integrated Joule heating rate, $W$, in the ionosphere

$$
W=J_{P} E=\frac{\Sigma_{P}}{\sum_{H}^{2}} J_{H}^{2} .
$$

In order to determine electric field and Joule heating in the ionosphere we require information about the height-integrated Hall current density and the Pedersen and Hall conductances. The heightintegrated Hall current, $J_{H}$, can be approximated by the equivalent ionospheric current (basically a thin-sheet Hall current) which is derived from magnetometer measurements. The technique is well developed, and the algorithm which is applied to the Greenland west coast magnetometer chain is described in detail by Popov et al. (2001). The ionospheric conductivities depend primarily on theelectron number density, $N_{e}$, and read (e.g., Watermann et al., 1993)

$$
\begin{aligned}
\sigma_{P} & =\frac{e}{B_{0}} N_{e}\left(\frac{v_{e} \Omega_{e}}{v_{e}{ }^{2}+\Omega_{e}{ }^{2}}+\right. \\
& \left.+\sum_{\text {ions }} \frac{v_{i} \Omega_{i}}{v_{i}^{2}+\Omega_{i}{ }^{2}} p_{i}\right) \\
\sigma_{H} & =\frac{e}{B_{0}} N_{e}\left(\frac{\Omega_{e}{ }^{2}}{v_{e}{ }^{2}+\Omega_{e}{ }^{2}}-\right. \\
& \left.-\sum_{\text {ions }} \frac{\Omega_{i}{ }^{2}}{v_{i}^{2}+\Omega_{i}^{2}} p_{i}\right) .
\end{aligned}
$$

Here, the subscripts «e» and «i» stand for electrons and various ion species with partial pressure (relative abundance) $p_{i}$, respectively. The ion population consists primarily of atomic and molecular oxygen and nitric oxide. The electron and ion gyro frequencies, $\Omega_{e}$ and $\Omega_{i}$, are determined by the geomagnetic field, $B_{0}$, which is accurately modeled by the International Geomagnetic Reference Field (IGRF), c.f. Mandea and Macmillan (2000). The electron and ion collision rates, $v_{e}$ and $v_{i}$, reflect mainly collisions with neutral atoms and molecules since the neutral number density in the lower ionosphere is orders of magnitude higher than the ion number density. The neutral number density is well represented by the MSIS-86 model (Hedin, 1987) and much less variable than the electron number density. The main unknown variable in these equations is therefore the electron density, $N_{e}$. Once the plasma density 
profile along the magnetic field line is known, e.g., from tomographic images, the height-integrated conductivities can be modeled via eq. (4.5), and the Joule heating rate can be inferred with the help of the equivalent ionospheric current via eq. (4.4). Work on this topic is currently in progress.

\section{Summary and outlook}

We compared seven cases of simultaneous tomographic images and ISR electron density maps from the high-latitude ionosphere and obtained in five cases good and in one case partial agreement. The lack of agreement could be traced back to the presence of plasma patches moving with a few hundred meters per second through the field-of-view. The tomographic method employed tends to reproduce the integrated effect of the plasma structures moving through the imaging plane during the satellite reception interval. But the method did not appear to produce results confused by the plasma motion and entirely misleading except for observations during the onset of a moderate substorm which constituted the worst agreement. Since a substorm can easily be detected in ground magnetic field measurements, such observations may possibly serve as a means to predict the performance of the tomographic method in specific cases. However, this needs to be further investigated using a larger observational data base. The result has potentially significant bearing on the application of the tomographic method at high latitudes not only to ionospheric imaging but also to investigations of the lower atmosphere.

We have further outlined a method to combine tomographic imaging with ground-based magnetometer observations to derive the ionospheric electric field and Joule heating rate. This requires accurate mapping of the ionospheric $E$ region, and it has yet to be confirmed that high-latitude tomography can reliably resolve the $E$ region plasma density distribution. A test and validation of $E$ region imaging will be performed in a way similar to the one described in this paper, namely by comparing tomographic images with ISR maps of $E$ region plasma density, electric field strength and Joule heating rates.

The assumption of negligible neutral wind speed is not always justified. From an analysis of Sondrestrom ISR measurements, Thayer (2000) deduced that neutral winds can reduce the transfer of electrical energy from the magnetosphere to the upper atmosphere by some $20 \%$ for moderate energy deposition rates $(<10 \mathrm{~mW} / \mathrm{m})$ and between $30 \%$ and $50 \%$ for higher deposition rates. Refinements to the method outlined here are needed in order to obtain a quantitatively more realistic assessment of the Joule heating rate.

\section{Acknowledgements}

The tomographic receivers on the Greenland west coast are operated by the Applied Research Laboratories, The University of Texas at Austin (ARL:UT), with financial support from the National Science Foundation (NSF) through grant ATM-9813864, and in collaboration with the Danish Meteorological Institute (DMI). The Sondrestrom incoherent scatter radar is operated by SRI International under the NSF Cooperative Agreement ATM-9813556 and in cooperation with DMI. The Greenland ground-based magnetometers are operated by DMI.

\section{REFERENCES}

AUSTEN, J.R., S.J. FRANKE and C.H. LIU (1988): Ionospheric imaging using computerized tomography, Radio Sci., 23, 299-307.

BERNHARDT, P.A., R.P. MCCOY, K.F. DYMOND, J.M. PICONE, R.R. Meier, F. Kamalabadi, D.M. Cotton, S. Charkrabarti, T.A. CoOK, J.S. Vickers, A.W. StePhan, L. KeRSLEy, S.E. PRYSE, I.K. WALKER, C.N. MitCHELl, P.R. STRAUS, H. NA, C. BISWAS, G.S. BUST, G.R. KRONSCHNABEL and T.D. RAYMUND (1998): Twodimensional mapping of the plasma density in the upper atmosphere with Computerized Ionospheric Tomography (CIT), Phys. Plasmas, 5, 2010-2021.

Bust, G.S., T.L. GaUssiran II and D.S. CoCO (1997): Ionospheric observations of the November 1993 storm, J. Geophys. Res., 102, 14,293-14,304.

Bust, G.S., C. COKER, D.S. CoCO, T.L. GAUSSIRAN II and T. LAUDERDALE (2001): IRI data ingestion and ionospheric tomography, Adv. Space Res., 27(1), 157-165.

Foster, J.C., M.J. Buonsanto, J.M. Holt, J.A. Klobuchar, P. Fougere, W. PAKula, T.D. RAYMund, V.E. Kunitsyn, E.S. ANDREEVA, E.D. TERESHCHENKO and B.Z. KHUDUKON (1994): RussianAmerican tomography experiment, Int. J. Imag. Syst. Tech., 5, 148-159.

FRIIS-CHRISTENSEN, E., Y. KAMIDE, A.D. RICHMOND and S. MATsushita (1985): Interplanetary magnetic field control of high-latitude electric fields and 
currents determined from Greenland magnetometer data, J. Geophys. Res., 90, 1325-1338.

HEDIN, A.E. (1987): MSIS-86 thermospheric model, $J$. Geophys. Res., 92, 4649-4662.

KELLY, J.D. (1983): Sondrestrom radar - initial results, Geophys. Res. Lett., 10, 1112-1115.

LEITINGER, R., G.K. HARTMANN, F.-J. LOHMAR and E. PUTZ (1984): Electron content measurements with geodetic Doppler receivers, Radio Sci., 19, 789-797.

MANDEA, M. and S. MACMILLAN (2000): International Geomagnetic Reference Field - the eight generations, Earth Planets Space, 52, 1119-1124.

Mitchell, C.N., D.G. JoNES, L. KeRSLEY, S.E. PRYSE and I.K. WALKER (1995): Imaging of field-aligned structures in the auroral ionosphere, Ann. Geophys., 13, 1311-1319.

POPOV, V.A., V.O. PAPITASHVILI and J.F. WATERMANN (2001): Modeling of equivalent ionospheric currents from meridian magnetometer chain data, Earth Planets Space, 53, 129-137.

PRYSE, S.E., L. KERSLEY, M.J. WILLIAMS, I.K. WALKER and C.A. WILLSON (1997): Tomographic imaging of the polar-cap ionosphere over Svalbard, J. Atmos. Terr. Phys., 59, 1953-1959.

THAYER, J.P. (2000): High-latitude currents and their energy exchange with the ionosphere-thermosphere system, J. Geophys. Res., 105, 23,015-23,024.

VASICEK, C.J. and G.R. KRONSCHNABL (1995): Ionospheric tomography: an algorithm enhancement, J. Atmos. Terr. Phys., 57, 875-888.

WATERMANN, J., O. DE LA BEAUJARDIÉRE and F.J. RICH (1993): Comparison of ionospheric electrical conductances inferred from coincident radar and spacecraft measurements and photoionization models, J. Atmos. Terr. Phys., 55, 1513-1520. 